\title{
Cultura y tradición crucera en el Condado de Huelva. Expresiones compartidas en torno al mes de mayo
}

Celeste Jiménez de Madariaga | Universidad de Huelva

Aniceto Delgado Méndez | Instituto Andaluz del Patrimonio Histórico

URL de la contribución <www.iaph.es/revistaph/index.php/revistaph/article/view/3677>

\section{RESUMEN}

A caballo entre la sierra y la costa, la comarca del Condado de Huelva se presenta como una campiña donde las actividades de transformación relacionadas con el olivo y la vid, la agricultura de secano y la ganadería, han jugado y configurado un territorio de enorme relevancia para el conocimiento de este espacio y su relación con las provincias andaluzas de Cádiz y Sevilla. Estos y otros aspectos, conforman la personalidad de una comarca en la que los rituales festivos vinculados con la cruz de mayo adquieren un notable interés, tanto por su extensión como su relevancia en los ciclos festivos de las localidades en las que se celebra.

El mes de mayo y los meses previos, son "tiempo de cruces" en el Condado, tiempo de fiesta, momentos para el disfrute colectivo y la afirmación de pertenencia a una localidad, a un barrio, o a una calle.

\section{Palabras clave}

Andalucía | Antropología | Condado de Huelva | Cruces de mayo | Huelva | Patrimonio inmaterial | Rituales festivos | 


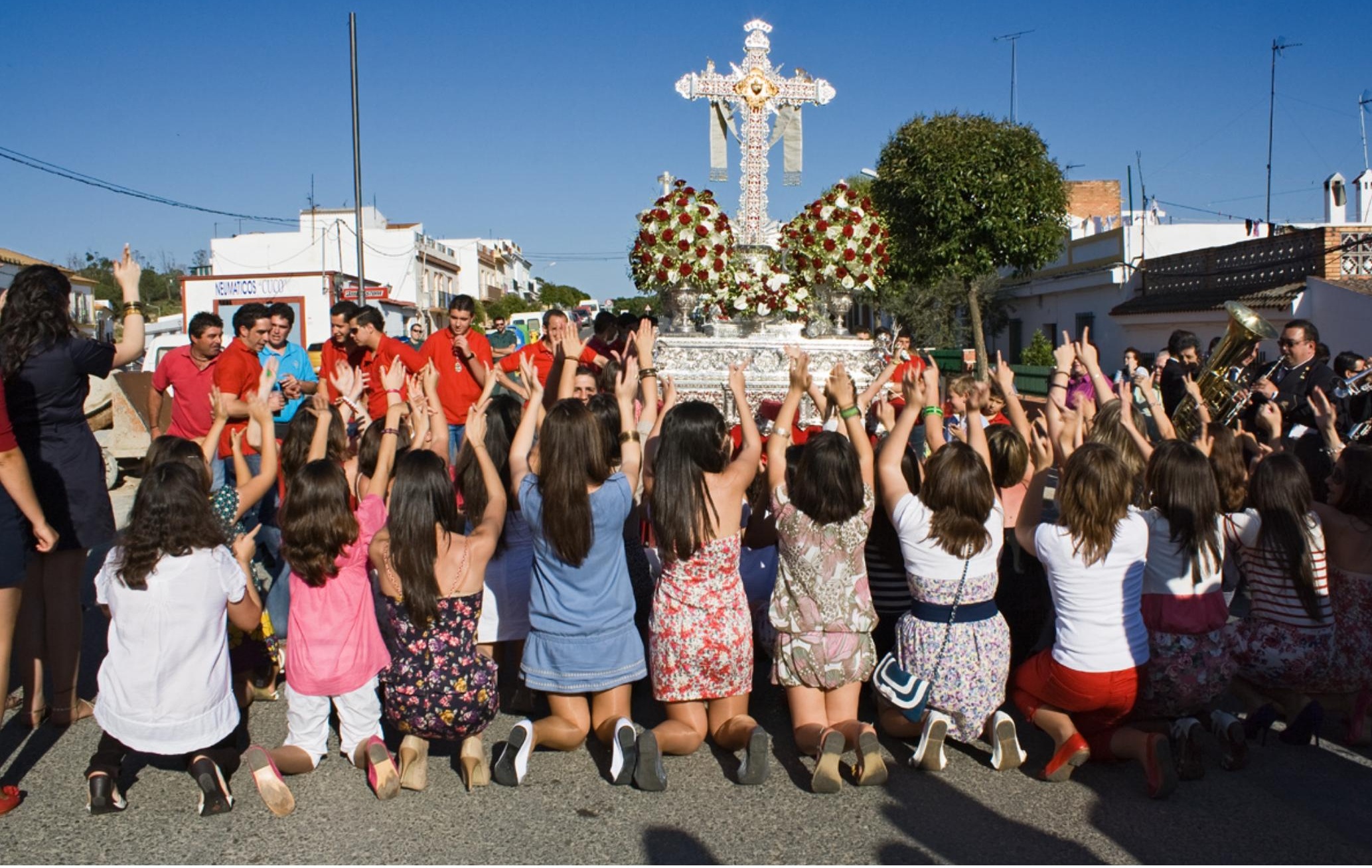

Cantando y bailando en honor a la Cruz de la calle Arriba (Lucena del Puerto) | foto todas las imágenes que ilustran este artículo, si no se indica lo contrario, pertenecen al Fondo Gráfico del IAPH (Proyecto Atlas del Patrimonio Inmaterial de Andalucía) 


\section{INTRODUCCIÓN}

Ya han traído la Santa Cruz de la calle de Las Huertas con qué estilo la han vestío que no hay otra como ésta. Todos se quedan mirando tan delicado madero que unas manos primorosas han hecho con tanto esmero. Todo el pueblo emocionado no deja de contemplar este bendito madero con las lágrimas saltás ${ }^{1}$

$$
1
$$

Copla dedicada a la Santa Cruz de la calle Las Huertas, fechada en los años 30 del siglo XX. Rociana del Condado.
Dentro de los diferentes rituales que ordenan el calendario festivo de la comarca del Condado de Huelva, adquieren protagonismo aquellos que giran en torno a las cruces de mayo. Este protagonismo viene representado no solo por el número de poblaciones en las cuales se desarrolla, sino por la relevancia que adquieren en los lugares donde se llevan a cabo. Bonares, Escacena del Campo, Lucena del Puerto, Manzanilla, la Palma del Condado, Paterna del Campo, Rociana del Condado, Villalba del Alcor y Villarrasa son algunas de las localidades de la comarca en las que las fiestas de Cruces se convierten en claro exponente de esta relevancia.

Aunque en la mayoría de las ocasiones se de protagonismo a estas celebraciones por su "belleza y esplendor", su importancia vendría marcada no solo por los aspectos formales que rodean a esta fiesta, sino por lo que significa para las poblaciones en las cuales el mes de mayo no es solamente una fecha, sino el tiempo extraordinario a través del cual se articulan y comparten sentimientos. Y aún más allá de los sentimientos y de las experiencias festivas compartidas, las cruces de mayo constituyen expresiones de pertenencia a barrios, calles, sectores sociales... que estructuran la sociedad local según el individuo se vincule a una u otra cruz.

Las fiestas de cruces de mayo, tanto para la comarca del Condado de Huelva como para otros territorios de la geografía onubense y andaluza, continúan siendo un referente en el ciclo festivo anual y de los modos de expresión de las identidades colectivas locales. La llegada de la primavera, la exaltación de la naturaleza y aquellos otros aspectos que tan bien definió Caro Baroja en su obra La estación del amor (1979) siguen reflejando el poder de un tiempo que tiene en la cruz, el árbol, las flores, las mujeres, la música, el baile y la fiesta en general su principal razón de ser.

Aunque es mayo el mes donde se desarrollan la mayoría de las celebraciones que giran en torno a la cruz, en la comarca del Condado también nos encontramos con poblaciones en las que será septiembre el mes elegido para ello, normalmente sobre el catorce que es cuando se celebra la exaltación de la Cruz.

\section{TIEMPOS Y ESPACIOS PARA LA CRUZ}

Los rituales festivos, lejos de reproducirse en el tiempo como meros espejos del pasado, siguen siendo un texto idóneo para el conocimiento de nuestra sociedad y para el conocimiento de aquellos colectivos que la conforman. En ellas, encontramos permanencias y transformaciones que nos muestran cómo estas manifestaciones reflejan los propios cambios y reproducciones 

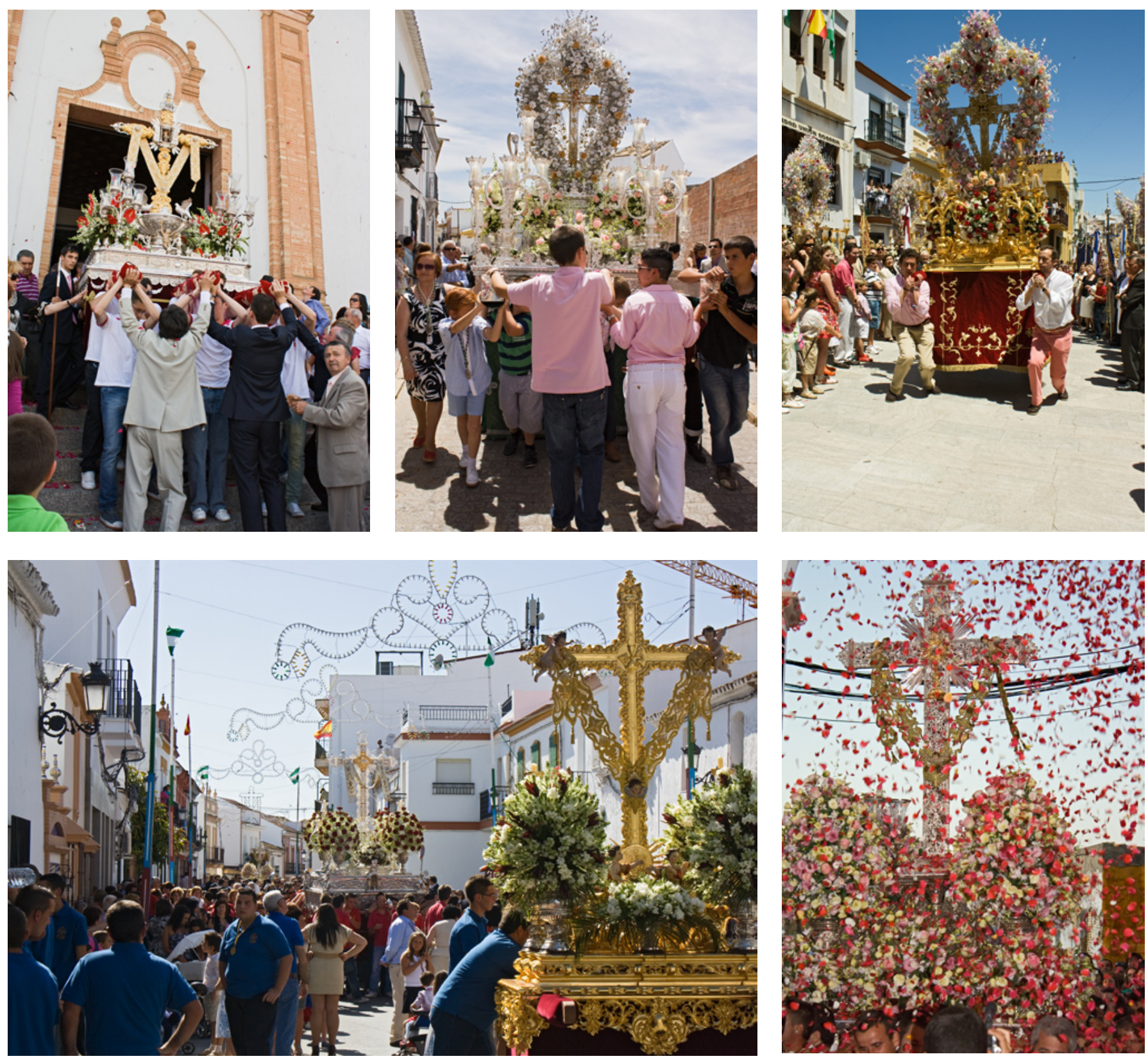

De arriba abajo, de izquierda a derecha: Salida de la Cruz de la calle La Fuente (Rociana del Condado) Niños con la Cruz de Arriba (Rociana del Condado) "Las caídas" (Bonares)

Procesión de las Cruces de Lucena del Puerto Lluvia de pétalos a la Cruz de la calle Malva en su capilla (Lucena del Puerto) 


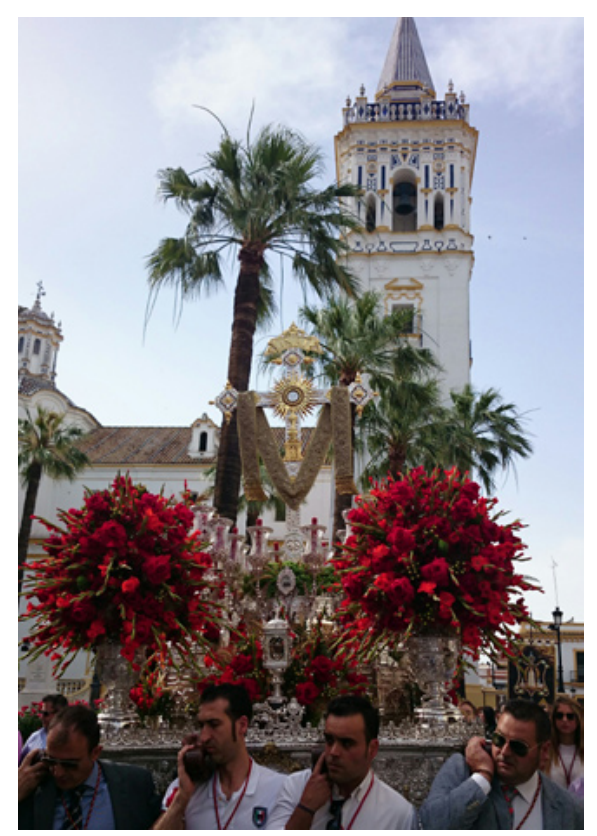

Santa Cruz de la calle Sevilla, junto a la torre de La Palma del Condado | foto Jesús Sánchez Márquez

Cruz del Rincón (Bonares)

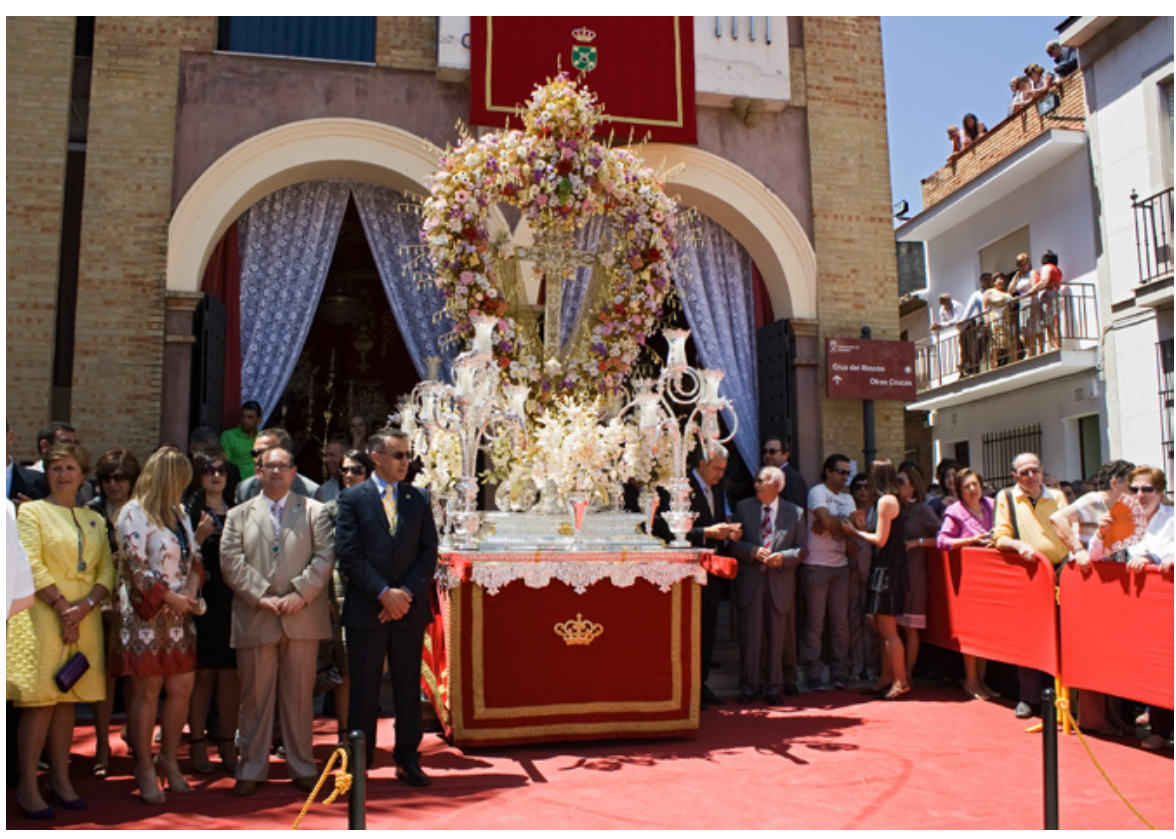

de estas sociedades, a la vez que nos permiten acercarnos a los significados de un patrimonio cultural -poco conocido e interpretado desde este punto de vista- que representa e identifica a numerosos colectivos.

Aunque la mayoría de las fiestas de Cruces se remontan a varios siglos de antigüedad, disponemos de escasa documentación histórica que date el origen de cada caso debido, entre otras cuestiones, a su carácter popular y espontáneo, ajenas a los registros historiográficos comunes en estas épocas. En la mayoría de las ocasiones, estas fiestas eran organizadas por la propia gente de los pueblos, familias y vecinos que se reunían y celebraban "su cruz" sin ningún control por parte de las instituciones religiosas y políticas. Es, precisamente, por el intento de controlar estas celebraciones festivas, cuando comienzan a citarse en documentos epistolares y oficiales, en la mayoría de los casos acusando el desatino y la falta de recato en los actos y expresiones festivas. Esta falta de fuentes documentales no reduce, sin embargo, la importancia de una fiesta que se convierte en uno de los principales acontecimientos dentro del ciclo festivo de un gran número de municipios de la comarca del Condado de Huelva. La falta de "oficialidad", la inscripción oficial de las hermandades o asociaciones que configuran los colectivos en torno a una cruz, no ha sido un impedimento para que éstas fueran motivos de identificación colectiva. Con independencia de que su inscripción se haya realizado en tiempos relativamente recientes (en muchos casos por facilitar su gestión), los orígenes suelen remontarse a épocas no definidas esencializando las celebraciones de las cruces de mayo a un pasado remoto. 


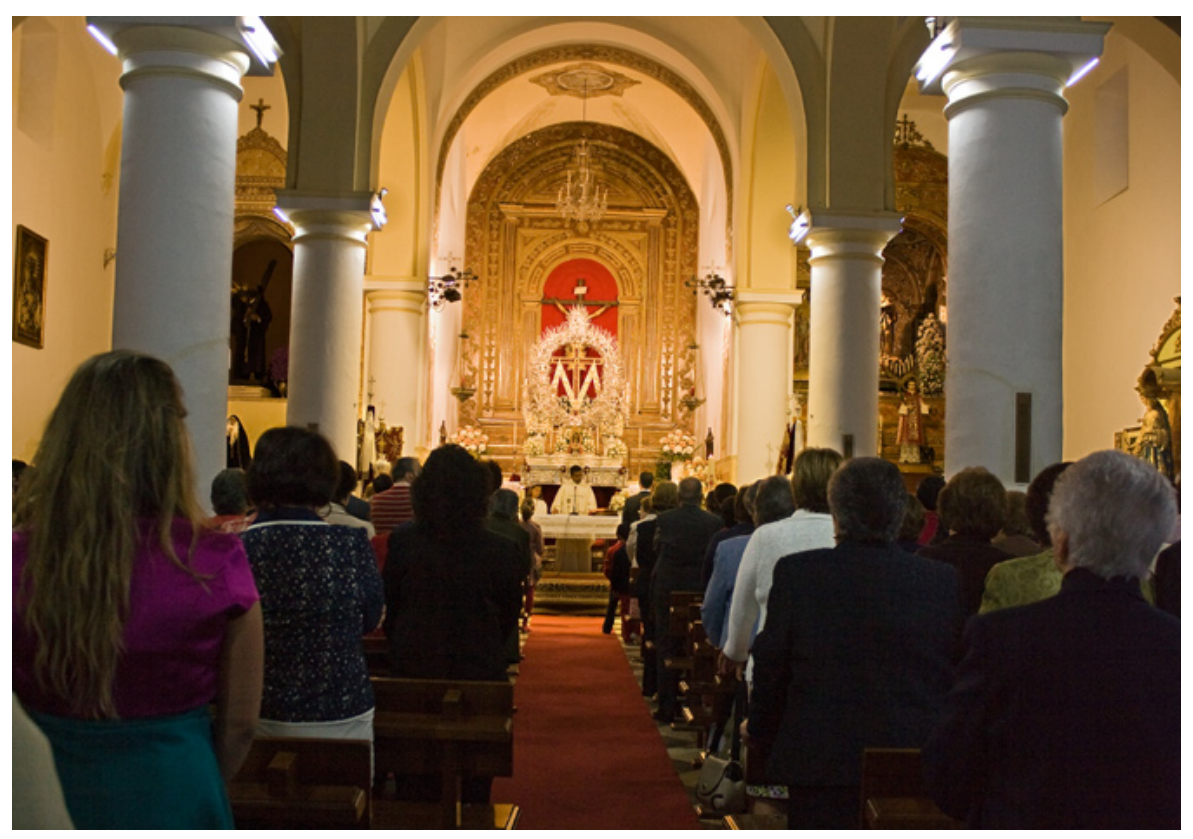

Esos orígenes en un pasado indefinido hace que, aún en la actualidad, las fiestas de las Cruces, como señalábamos con anterioridad, mezclen elementos sagrados y profanos, constituyendo una clara exaltación de la naturaleza, la renovación de la vida, la fertilidad y el amor. Las interpretaciones sobre este ritual festivo son diversas según se vinculen a aspectos míticossimbólicos: por un lado, se asocia a la diosa Maya en interpretaciones griega o romana, pero, por otro lado, se "cristianiza" este posible origen sustituyendo el árbol del "mayo" por la "cruz" (madero) de Cristo, de manera que se conmemora la búsqueda de la Cruz donde fue crucificado Jesucristo por parte de Elena, hija del emperador Constantino I el Grande. Las cruces de mayo se convierten en uno de los más claros ejemplos de cristianización de ritos paganos orientados al culto a la fertilidad, al esplendor de la naturaleza, en definitiva al nuevo contexto que define y presenta la estación primaveral. Sea como fuere, de lo que no cabe duda es de la importancia de las fiestas de cruces de mayo como momento festivo de un gran número de poblaciones.

La vitalidad de este ritual viene acompañada de un amplio abanico de elementos materiales e inmateriales que definen un patrimonio poco conocido y en raras ocasiones valorado.

La relevancia de esta manifestación debe ser entendida no solamente en el marco del contexto ritual, sino también en toda una serie de preparativos que son tan o más importantes que el propio desarrollo de la fiesta. La preparación de las "capillas", de las "habitaciones", las reuniones previas de
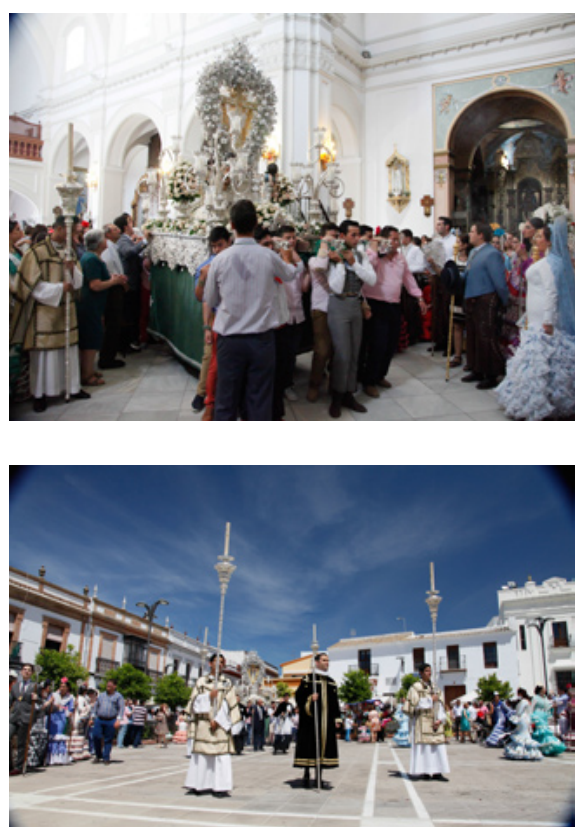

Acto litúrgico previo a la procesión (Villarrasa)

Fiestas 2014 de la Santa Cruz de Arriba de Rociana del Condado | fotos Archivo de la Hermandad (facilitadas por Manolo de Miguel) 
Procesión de la Santa Cruz de la calle Cabo de La Palma del Condado, 2013 | foto David Limón Suárez

Salida procesional, desde su capilla, de la

Santísima Cruz de Abajo (Paterna del Campo) | foto María José Sánchez Morato

Cruceros de la Calle Candado (Rociana del Condado)

Romerito de la Cruz de Arriba (Villarrasa) vecinas para perfilar todo lo que rodea a las cruces, la limpieza de los bienes muebles vinculados a esta celebración (cruces, pasos, imágenes, estandartes...), así como la contratación de fuegos artificiales, bandas de música y otros, conforman un diverso mundo solamente descifrado desde el sentimiento crucero.

Respecto al propio desarrollo del ritual y la relación entre la cruz, las connotaciones simbólicas asociadas al mes de mayo y la naturaleza, podemos destacar en esta comarca la relación entre el ámbito urbano y el rural, evidente en numerosas celebraciones en campos o parajes cercanos a la localidad. Es lo que sucede por ejemplo en Bonares con el "romerito", nombre que recibe una romería que tiene lugar dentro del ciclo festivo crucero y que traspasa las fronteras de la ciudad estableciendo una estrecha relación con el medio natural. También en Rociana del Condado se lleva a cabo "el romerito" y en ellas adquiere importancia las "coplas de pique".
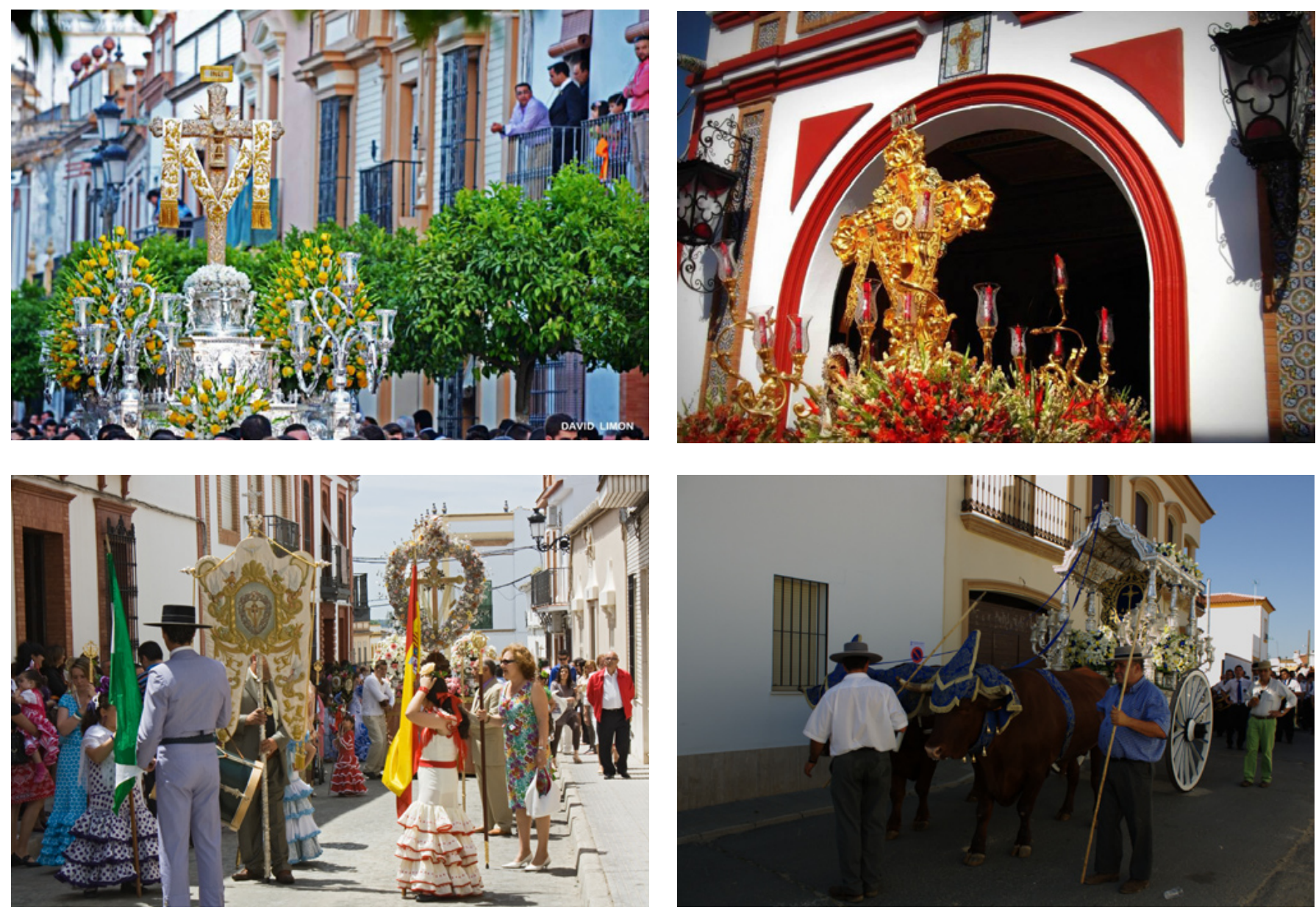
Esta estrecha relación ahonda en la enorme importancia que ha tenido para las culturas campesinas el ciclo agrícola y todo lo que rodea a este mundo tan vinculado al aprovechamiento de los recursos endógenos.

En este sentido, también es habitual que los protagonistas del ritual se acerquen al campo para encontrar, en el entorno más cercano, elementos de la vegetación que sirvan para engalanar las cruces, pasos, capillas y otros elementos que posteriormente se enseñarán o procesionarán.

Otro aspecto relevante que diferencia a este ritual de unas localidades a otras es la existencia de una o varias cruces que identifican a dos o más colectivos dentro de un pueblo. En ese sentido, encontramos dos posibilidades: localidades con celebraciones de cruces duales, es decir, sociedades divididas simbólicamente en dos cruces; y localidades donde hay más de dos cruces vinculadas a barrios o calles (a la par que a sectores sociales diferenciados). Así, en la misma comarca del Condado observamos casos

Traslado de la Cruz de la Calle Cabo (La Palma del Condado)

Romerito de la Cruz de la Calle Sevilla (La Palma del Condado)

Niños con la Cruz de la calle Malva (Lucena del Puerto)

Fiestas 2014 de la Santa Cruz de Arriba de Rociana del Condado | fotos Archivo de la Hermandad (facilitadas por Manolo de Miguel)
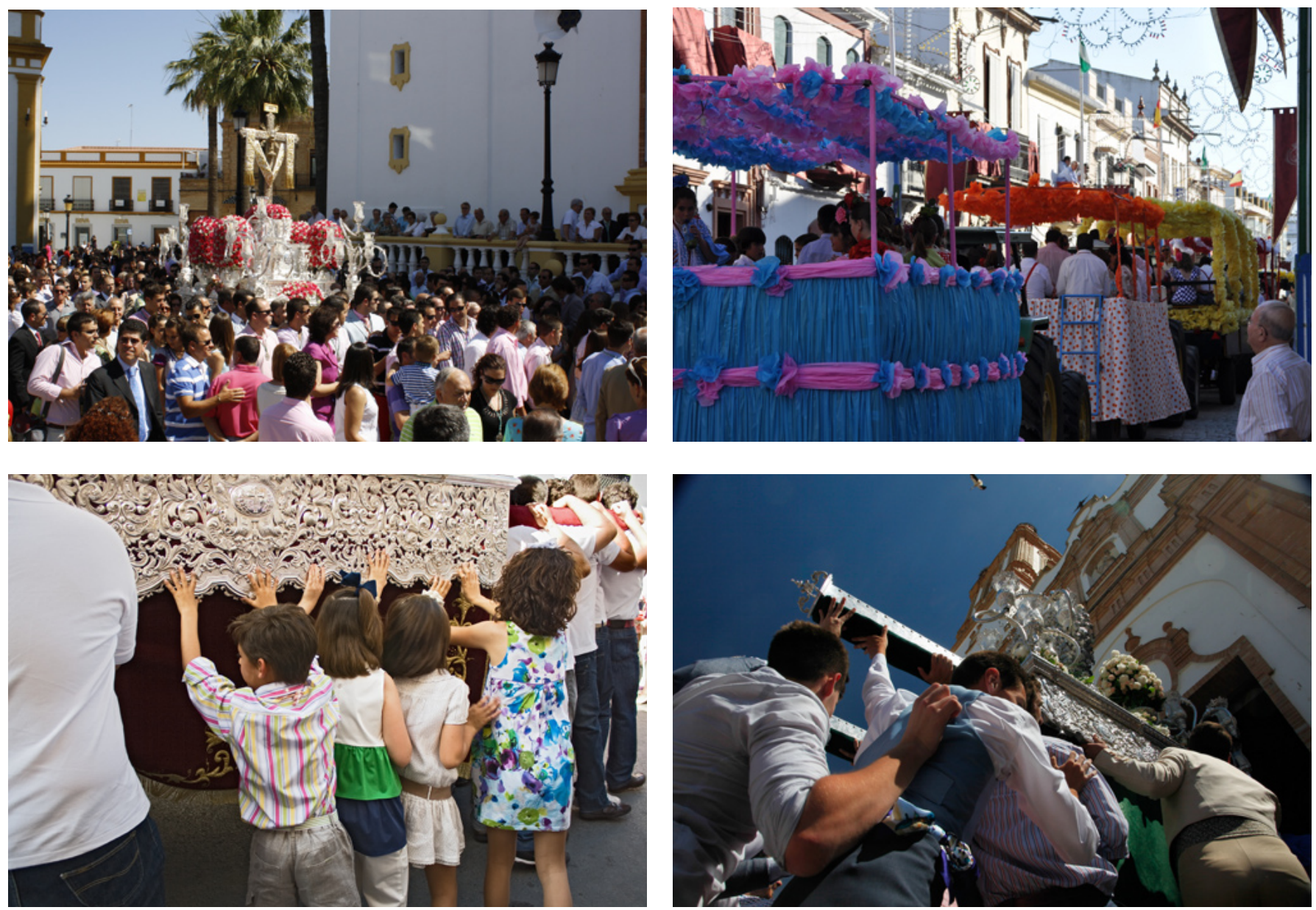

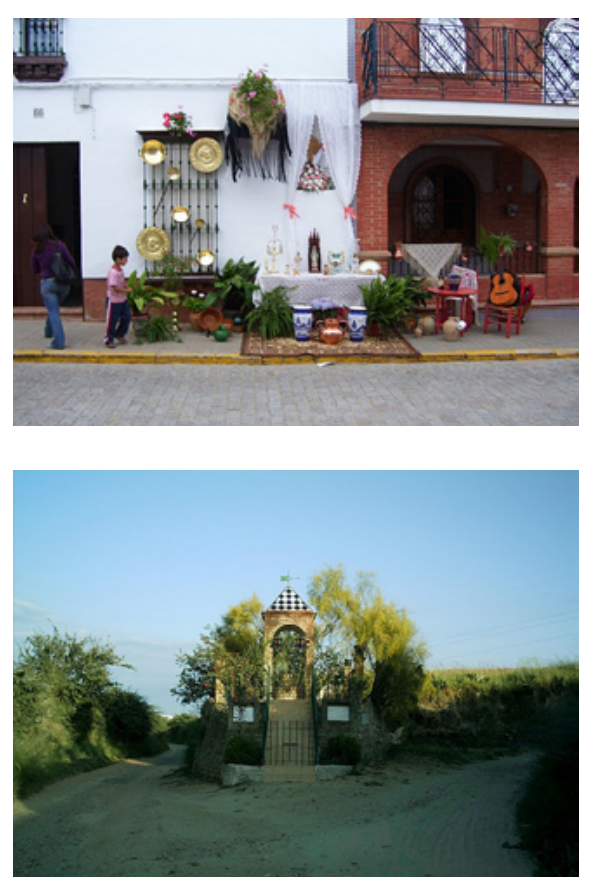

Cruz de la Calle Villalba (Manzanilla). Dichas cruces, se encuentran durante todo el año entronizadas en unas hornacinas situadas de las fachadas de algunas casas de la Villa

Capilla de la Santa Cruz del Camino del Puerto (Manzanilla). Dicha capilla se encuentra situada en el camino del Puerto | fotos Juan Luis Romero García de localidades con dos cruces o que lo denominamos "rituales de cruces duales", tales como en La Palma del Condado (Cruz de la Calle Cabo y Cruz de la Calle Sevilla) y Villarrasa (Cruz de Arriba y Cruz del Campo); y localidades con varias cruces o lo que denominamos "rituales de cruces múltiples" como en Rociana del Condado (donde había nueve cruces de mayo, aunque ahora solo cinco, entre las que adquieren especial relevancia la Cruz de la Calle de la Fuente y la Cruz de la Calle de Arriba). Esta diferenciación no solo influye en las diferenciaciones simbólicas de los espacios sociales y territoriales, sino en las maneras en que se expresan las rivalidades. Una de las características de las fiestas de cruces es la competencia por el mayor esplendor y la riqueza ornamental de la cruz propia en contraposición con la otra cruz u otras cruces, lo que tradicionalmente se ha denominado "el pique". La rivalidad es más intensa en los casos de poblaciones de "cruces duales" con la sociedad local divida en dos sectores claramente enfrentados, mientras que en las poblaciones con "cruces múltiples", las posibilidades de pertenecer e identificarse con las diversas cruces diluye las rivalidades, si bien, en este último caso, siempre suele destacarse dos o tres cruces que adquieren cierto protagonismo respecto al resto.

La importancia simbólica que adquieren las cruces en el imaginario colectivo local tanto como elemento diferenciador respecto a otras localidades (la fiesta en sí misma), a la vez que elemento diferenciador dentro de la propia localidad (entre las diversas cruces), produce que las cruces no sean solamente un elemento efímero sino que trascienda la propia fiesta $\mathrm{y}$, de algún modo, estén presentes en todo el ciclo anual como símbolo relevante e identificador local. Al mismo tiempo, el hecho de que en esta modalidad festiva estén presentes varias cruces multiplica las secuencias, actos y protagonistas festivos que en el caso de localidades con dos cruces se repiten paralelamente en una y otra cruz.

A lo que el elemento de la cruz propiamente dicha se refiere, encontramos asimismo dos posibilidades: "capillas efímeras", donde la cruz se expone en improvisadas capillas situadas en ámbitos domésticos; y las "capillas permanentes" hechas expresamente para albergar la cruz. En este último caso, algunas capillas mantienen cierta actividad durante la mayor parte del año, a ellas se acercan feligreses y hermanos para celebrar diferentes actos tanto cívicos como religiosos. Se convierten, así, en espacios o centros de sociabilidad donde se llevan a cabo reuniones y encuentros, lo que refuerza aún más la unión entre los miembros que integran la cruz. Ejemplos de este tipo los encontramos en la Palma del Condado y en Bonares.

Y por último, otro de los elementos que podemos destacar en estas celebraciones festivas son sus protagonistas y, entre ellos, el papel atribuido a la mujer. La vinculación simbólica de las fiestas de las cruces con la primavera y la reproducción de la naturaleza, se extiende hacia la mujer como, 


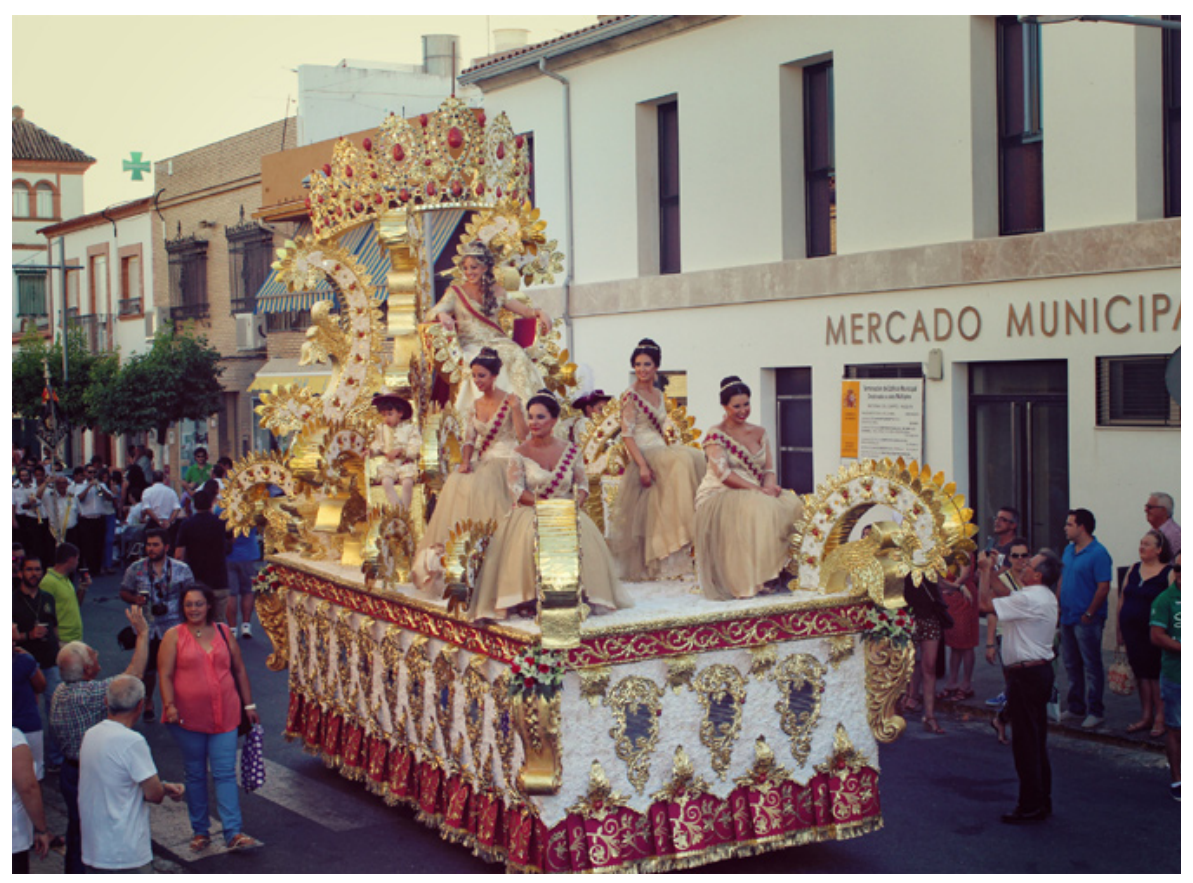

asimismo, reproductora de vida. La mujer joven está presente en todas las fiestas de cruces, siendo una de sus protagonistas fundamentales y estando presentes en todos los momentos de importancia del ritual (a veces con el requisito de la soltería). Según los casos, se elige a la "reina", "mayordoma" o "moza", que representan la belleza y pureza, casi siempre junto a un acompañante, también joven, con el que forma pareja. Pero, además, la actividad de la mujer en las cruces es de fundamental importancia en la organización de la fiesta en sí. Tanto en la ornamentación de las capillas y cruces, como en la preparación de aquellos otros aspectos estrechamente vinculados a este ritual (gastronomía, indumentaria, coplas, etc.), la mujer se convierte en la verdadera artífice y conocedora de todo lo que rodea a esta expresión cultural. Los roles de género y edad, con sus respectivas funciones, acompañan al desarrollo de una celebración que además de registrar la división de procesos rituales, define prácticas conocidas y transmitidas de unas generaciones a otras.

\section{CONSIDERACIONES FINALES}

Teniendo en cuenta las dinámicas sociales y las transformaciones experimentadas en los últimos años, pensamos que lejos de su desaparición, en la Comarca del Condado, las cruces de mayo están en plena efervescencia y vigor, siguen formando parte del universo festivo de esta comarca onubense. Las fiestas de las cruces no son un símbolo arcaizante del pasado, sino un

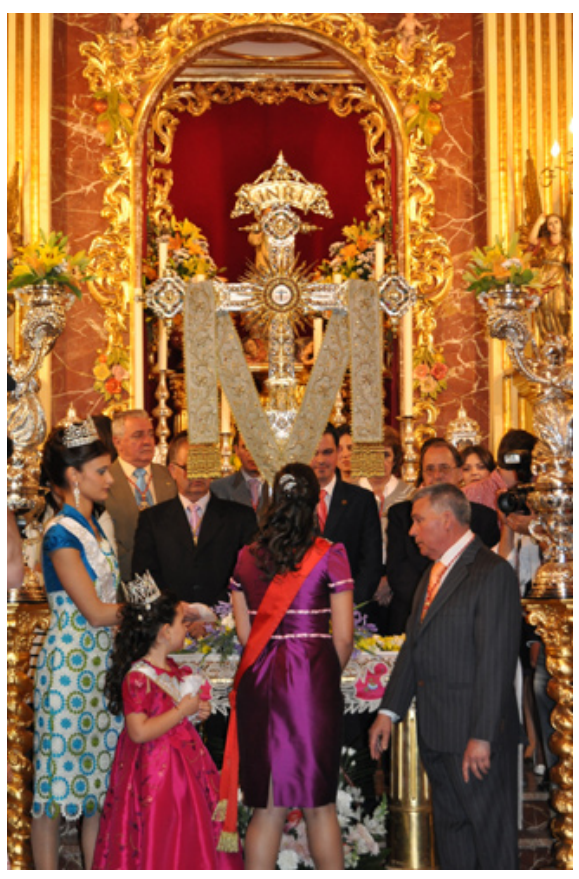

Carroza Reina 2014 en Paterna del Campo | foto Hdad. de la Santa Cruz de la Victoria de Cristo

Acto de coronación de la Reina de la Cruz de la Calle Sevilla (La Palma del Condado) 
reflejo de cómo los rituales se reinterpretan desde el presente con nuevos significados y formas de expresión. El ritual se adapta así a los nuevos tiempos, necesidades y usos. Una de las nuevas formas de reinterpretación de estas fiestas es desde la óptica del patrimonio cultural. En el Condado, las fiestas de las cruces constituyen claros exponente del patrimonio cultural identificador de la comarca (por su amplia presencia y relevancia) y de las localidades donde se celebran. En ellas se conjugan elementos del patrimonio material tanto inmueble (capillas y locales), como del patrimonio material mueble (las cruces, estandartes, vestimentas, ornamentos, etc.), junto a un amplio despliegue de elementos del patrimonio inmaterial (coplas, músicas, gastronomía, técnicas decorativas, etc.), de manera que lo material y lo inmaterial se entremezclan continuamente.

Las cruces de mayo además de por su riqueza ornamental y visual deben ser comprendidas por su significación social, como momentos que definen y representan a colectivos con unas necesidades y unas características propias. Esta diversidad respecto a la manera de expresar sentimientos y experiencias compartidas, otorga a este ritual un valor que debe ser comprendido y analizado desde perspectivas cuya mirada no individualice contextos sino que aboguen por la multiplicidad de significados.

Las prácticas rituales asociadas a estos momentos festivos describen modelos que constituyen un magnífico exponente de la diversidad y riqueza de esta comarca, a la vez que definen la complejidad de unos bienes sobre los que se deberían formular propuestas que garantizaran su salvaguarda. Las dificultades que pueden acarrear el conocimiento y la protección de estos bienes no debiera ser un impedimento para la puesta en marcha de mecanismos que afrontaran el diseño de un nuevo marco en el que las fiestas de cruces de mayo fueran comprendidas y valoradas como un elemento más de nuestro patrimonio cultural.

La organización de varias jornadas encaminadas al conocimiento y la difusión de los diferentes elementos que componen esta celebración en el marco de esta comarca, es otra prueba de la importancia que los diferentes colectivos relacionados con esta celebración otorgan a esta fiesta. Celebrados en la Palma del Condado, Bonares y Rociana, en lo que respecta a la comarca del Condado, estos encuentros han servido para poner de manifiesto la importancia que ha tenido y tiene esta fiesta.

Con sus "romeritos" y sus "habas pochas", con sus "coplas de pique" y sus "capillas", con sus "cabezás" y sus "caídas", con sus "habitaciones" y sus "procesiones", con sus "mayordomas" y sus "carrozas", las fiestas de cruces de mayo dibujan contextos rituales en los que la Comarca del Condado demuestra sus formas de ser y sentir. 


\section{BIBLIOGRAFÍA}

- AGUDO TORRICO, J. (2000) Romerías, ferias y fiestas (significados y funciones de las fiestas andaluzas). En Gran Enciclopedia Andaluza del siglo XXI. Tomo 6. Sevilla: Ediciones Tartessos, 2000, pp. 257-303

- CARO BAROJA, J. (1979) La estación del amor (fiestas populares de mayo a S. Juan). Madrid: Taurus, 1979

- CAMPo TEJEDOR, A. DEL; CORPAS, A. (2005) El mayo festero. Sevilla: Fundación José Manuel Lara, 2005

- DELGADO MÉNDEZ, A. (2007) Las fiestas de las cruces de mayo: entre el pasado y el presente. En La cruz de mayo en la provincia de Huelva. Actas I Jornadas de cruces de mayo. La Palma del Condado: Ayuntamiento de la Palma del Condado, 2007, pp. 13-30

- FERNÁNDEZ DE PAZ, E. (1996) Las cruces de mayo en Berrocal. Demófilo. Revista de Cultura Tradicional de Andalucía, n. ${ }^{\circ} 19,1996$, pp. 101-112

- PAZ SÁncheZ, J. J. (2000) El ciclo festivo de Almonaster La Real (Huelva): Un exponente de religiosidad popular como aglutinador social. En GONZÁLEZ CRUZ, D. (ed.) Religiosidad y costumbres populares en Iberoamérica. Huelva: Universidad de Huelva y Centro de Estudios Rocieros, 2000, pp. 323-346

- JIMÉnEZ DE MADARIAGA, C. (2004) Las Fiestas de Cruces en la provincia de Huelva. En GONZÁLEZ CRUZ, D. (ed.) Las cruces de mayo en España. Huelva: Universidad de Huelva, Servicio de Publicaciones, 2004, pp. 97-118

- JIMÉNEZ DE MADARIAGA, C. (2011) Rituales festivos y confrontación social. Cruces de mayo de la provincia de Huelva. Gazeta de Antropología [en línea], n. ${ }^{\circ} 27$ (2), 2011, artículo 31 <http://www.gazeta-antropologia.es/?p=1425> [Consulta: 13/08/2015]

- RODRígueZ BECERRA, S. (2004) Las Cruces de Mayo en Andalucía. En GONZÁLEZ CRUZ, D. (ed.) Las cruces de mayo en España. Huelva: Universidad de Huelva, Servicio de Publicaciones, 2004, pp. 57-80

- VELASCO MAILlO, H. M. (1982) A modo de introducción. Tiempo de fiesta. En VELASCO MAILLO, $\mathrm{H}$. M. (ed.) Tiempo de fiesta (ensayos antropológicos sobre las fiestas en España). Madrid: Tres-Catorce-Diecisiete, 1982, pp. 5-25
Nota de la redacción

Celeste Jiménez de Madariaga, coautora del artículo, es investigadora principal del Proyecto de Excelencia de la Junta de Andalucía de la convocatoria 2011 (modalidad Motriz) financiado por la Consejería de Economía, Innovación, Ciencia y Empleo de la Junta de Andalucía y el Ministerio de Economía y Competitividad. 